\title{
Awareness and Practice Patterns of Family Planning Methods among Antenatal Women in Indian Community: Are We Hitting the Bull's Eye?
}

\author{
Deepti Choudhary, Reena Pal, Neerja Goel
}

\begin{abstract}
A questionnaire-based cross-sectional survey was undertaken to assess the awareness and practice patterns of family planning among the antenatal women in North India. The study included 400 respondents. Three-fourths of the respondents $(74.2 \%, n=297)$ were aware of family planning methods. Condoms were the most commonly used family planning method (78.2\%), while intrauterine devices and oral contraceptive pills were used by $25.5 \%$ and $16.7 \%$ respondents, respectively. The main reasons cited for not using contraception were inadequate knowledge and fear of side-effects. Post counseling, $90.5 \%(n=362)$ of the respondents clearly conveyed their desire to use one of the family planning methods in the postpartum period. Awareness and acceptance of family planning methods in the Indian community needs strengthening. Family planning counseling during antenatal check-up is likely to increase the acceptance of family planning methods in the postpartum period.
\end{abstract}

(Biomed J 2015;38:356-358)

Key words: antenatal period, antenatal women, awareness, family planning services, population control, questionnaire-based survey

$F_{\text {ant }}^{a}$ amily planning allows individuals and couples to anticipate and attain their desired number of children and the spacing and timing of their births. It is achieved through the use of contraceptive methods. ${ }^{[1]}$ Family planning offers a positive view of reproductive life and enables people to make informed choices about their reproduction and well-being. Family planning is one of the important measures to contain overgrowing population. Though the Government of India launched a National Family Welfare Program way back in 1950s to accelerate the economic and social development by reducing the population growth, the program could not achieve the expected success with an obvious reason - multi-linguistic, multi-religious, and multi-ethnic nature of the Indian population. Antenatal period is an important aspect for family planning awareness as a pregnant woman is likely to be most receptive for contraception usage in the postpartum period. So, we designed a questionnaire-based study to assess the awareness and practice patterns of family planning among the antenatal women in North India.

\section{METHODS}

\section{Study design}

A cross-sectional questionnaire-based survey was conducted from May to December 2012.

Setting

Hospital-based survey in the antenatal clinic of a tertiary teaching hospital in North India

\section{Sample size}

Sample size was calculated using the formula given below. Considering 50\% awareness of the respondents about family planning methods $(p=0.5)$, the sample size was calculated to be 384 with $95 \%$ confidence level and $5 \%$ precision of estimate $(d=0.05)$ :

$$
N=\frac{Z^{2}(p)(1-p)}{d^{2}}
$$

From the Department of Obstetrics and Gynecology, Guru Teg Bahadur Hospital and University College of Medical Sciences, Dilshad Garden, Delhi, India

Received: Feb. 24, 2014; Accepted: Jul. 31, 2015

Correspondence to: Dr. Deepti Choudhary, Department of Obstetrics and Gynecology, Guru Teg Bahadur Hospital and University College of Medical Sciences, Dilshad Garden, Delhi, India. Dilshad Garden, Delhi - 110 095, India. Tel: 91-11-22582972; Fax:

91-11-22590495; E-mail: dr.deeptichoudhary@ gmail.com

DOI: $10.4103 / 2319-4170.162485$ 


\section{Participants}

Four hundred antenatal women attending the antenatal clinic of a tertiary teaching hospital in North India.

\section{Questionnaire}

The questionnaire consisted of two parts. The first part consisted of questions about demographic data (name, age, religion, socio-economic status, occupation, and parity of respondents). The second part consisted of questions to assess their knowledge of family planning methods, sources of information, and their intention to adopt family planning methods in the postpartum period after being counseled. The questionnaire and ethical concerns were discussed in the departmental meeting; the questionnaire was approved after deliberate discussions.

The respondents were surveyed by the authors and trained assistants using pre-tested questionnaires.

\section{RESULTS}

The study included 400 respondents who agreed to fill the questionnaires. The mean age of the respondents was $25.6 \pm 3.2$ years. The age of respondents ranged from 18 to 40 years; majority of them $(90.2 \%, n=361)$ were between 21 and 30 years of age. All the respondents were married and majority $(76.0 \%, n=304)$ of them were multiparous.

Three-fourths of the respondents $(74.2 \%, n=297)$ were aware of family planning methods. Television was reported to be their main source of information (47.7\% respondents), followed by friends (34.2\%). Other sources of information were radio $(6.7 \%)$, magazines $(4.5 \%)$, posters $(3.5 \%)$, newspaper $(2.3 \%)$, and pamphlets $(0.7 \%)$. The literacy rate and awareness of family planning methods among the respondents were $85.5 \%(n=342)$ and $74.2 \%(n=297)$, respectively - illiterate $(n=58$, awareness $=46.5 \%),<5^{\text {th }}$ class $(n=138$, awareness $=76.8 \%)$, matriculation $(n=113$, awareness $=75.2 \%)$, senior secondary $(n=54$, awareness $=85.1 \%)$, and graduate $(n=37$, awareness $=89.1 \%$ ). There was a significant difference in awareness of family planning methods in the illiterate group as compared to the literate group $(27 / 58,46.5 \%$ vs. $270 / 342$, $78.9 \% ; p<0.0001$ Chi-square test). Most of the respondents belonged to low socio-economic status $(80.7 \%)$. The benefits of family planning, as conveyed by the respondents $(n=297)$ who were aware of family planning methods, were: Birth spacing $(n=275,92.5 \%)$, limiting family size $(n=119$, $40.0 \%)$, preventing unwanted pregnancy $(n=75,25.2 \%)$, healthy mother and child $(n=30,10.1 \%)$, reducing the risk of mother or newborn child $(n=11,3.7 \%)$, and preventing over population $(n=14,4.7 \%)$. Seventy-nine $(26.5 \%)$ respondents did not specify any reason (the sum may be more than 297 as a number of respondents conveyed more than one benefit of family planning).

Most of the respondents who were aware of family planning methods had knowledge of condoms (87.9\%), intrauterine devices (IUDs; 71.0\%) and oral contraceptive pills (OCPs; $57.6 \%$ ). Awareness about other methods including injectables (22.6\%), natural (16.8\%), and sterilization $(16.8 \%)$ was low [Table 1]. Though $74.2 \%(n=297)$ respondents were aware of family planning methods, 216 respondents $(72.7 \%, 216 / 297)$ reported to have used some form of family planning method earlier. Condoms were the most commonly used family planning method $(78.2 \%)$, while IUDs and OCPs were used by $25.5 \%$ and $16.7 \%$ respondents, respectively [Table 1]. There were $27.3 \%$ respondents who never used contraceptives despite being aware of family planning methods. The reasons cited by most of them, who were aware of family planning methods but were not practicing them $(n=81)$, for not using contraception were: Lack of knowledge $(n=54$, $66.7 \%)$, fear of side effects $(n=38,46.9 \%)$, religious beliefs $(n=18,22.2 \%)$, opposition from husband ( $n=16$, $19.7 \%)$, unnecessary procedure $(n=15,18.5 \%)$, and high cost $(n=5,6.1 \%)$; the sum of responses is more than 81 as many respondents cited more than one reason for not using contraception. Only 15 of the 81 respondents who reported to have never used contraception despite being aware of them actually confessed that they did not wish to use them. After having been explained about family planning methods, $90.5 \%(n=362)$ of the respondents clearly conveyed their desire to use one of the family planning methods in the postpartum period. IUDs $(n=252,69.7 \%)$ and OCPs $(n=180,49.7 \%)$ were the most commonly sought family planning methods by the respondents in the postpartum period [Table 2].

Table 1: Awareness of various family planning methods among the respondents

\begin{tabular}{|c|c|c|c|c|}
\hline \multirow[t]{2}{*}{$\begin{array}{l}\text { Family planning } \\
\text { methods }\end{array}$} & \multicolumn{2}{|c|}{$\begin{array}{l}\text { Awareness among } \\
\text { respondents } \\
(n=297)\end{array}$} & \multicolumn{2}{|c|}{$\begin{array}{l}\text { Practice patterns of } \\
\text { contraceptive use among } \\
\text { respondents }(n=216)\end{array}$} \\
\hline & Number* & Percentage & Number* & Percentage \\
\hline Condoms & 261 & 87.90 & 169 & 78.2 \\
\hline Intrauterine devices & 211 & 71.00 & 55 & 25.5 \\
\hline Oral contraceptive pills & 171 & 57.60 & 36 & 16.7 \\
\hline Sterilization & 67 & 22.60 & \# & \# \\
\hline Injectables & 50 & 16.80 & 5 & 2.3 \\
\hline Natural & 50 & 16.80 & 31 & 14.4 \\
\hline
\end{tabular}

*: The sum is more than 297 as many respondents were aware of or were using more than one family planning method. \#: As the respondents were antenatal women, question of sterilization as a previous practice does not arise 
Table 2: Family planning methods to be considered by the respondents in the postpartum period

\begin{tabular}{lcc}
\hline Type of contraception & No. of respondents (362)* & Percentage \\
\hline IUD & 252 & 69.6 \\
OCP & 180 & 49.7 \\
Sterilization & 102 & 28.1 \\
Condom & 45 & 12.4 \\
Injectable & 9 & 2.4 \\
Natural & 5 & 1.38
\end{tabular}

*: The sum is more than 362 as many respondents conveyed to consider more than one family planning method. Abbreviations: IUD: Intrauterine device; OCP: Oral contraceptive pills

\section{DISCUSSION}

The 2005-2006 National Family Health Survey (NFHS-3) showed that knowledge of contraception is universal in India; however, there was $74.2 \%$ awareness of family planning methods among the respondents in our study. ${ }^{[2]}$ Our hospital caters mainly to the underprivileged society of east Delhi and western Uttar Pradesh, as evident by the socio-economic status of respondents in our study $-80.7 \%$ respondents belonged to low socio-economic status. Moreover, $46.5 \%$ of the respondents in our study were illiterate. We believe that low socio-economic status and illiteracy among the respondents in our study were responsible for low family planning awareness. This highlights the urgent need to further strengthen the family planning services to impregnate this group of population.

Television and friends were the main sources of information for family planning methods in our study, while radio, magazines, posters, newspaper, and pamphlets were proved futile in spreading knowledge. Garg et al., in their cross-sectional questionnaire-based survey to get insight into apathy of men toward non-scalpel vasectomy, also suggested that circulation of information about family planning by word of mouth is of paramount importance. ${ }^{[3]}$ Tuladhar et al., in their cross-sectional descriptive study of awareness and practice of family planning methods, also concluded that electronic media and friends play a vital role in spreading the awareness. ${ }^{[4]}$

There were 66 out of 81 respondents in our study who were not using contraceptives because of certain reasons; inadequate knowledge and fear of side effects were the most cited reasons for this. This is a group which we need to concentrate the most when the strategies for family planning awareness are formulated. A small effort to alleviate their concerns will definitely help them adopt family planning methods.

Antenatal period provides a unique opportunity to make the women understand the benefits of family planning as they are most receptive during their pregnancy. This will also help them prepare to adopt contraceptive methods in the postpartum period. In our study, $90.5 \%$ of the respondents clearly conveyed their desire to use one of the family planning methods in the postpartum period after proper counseling. We believe that antenatal visit of the pregnant women should be taken as a unique opportunity to spread knowledge about family planning services.

\section{Acknowledgment}

We are thankful to Dr. Shalini Rajaram, Dr. Balkesh Rathi, and Dr. Himsweta Srivastava for their help in this research project.

\section{REFERENCES}

1. Available from; http://www.who.int/topics/family_planning/en/ [Last accessed on 2013 Aug 18].

2. International Institute for Population Sciences (IIPS) and Macro International. 2007. National Family Health Survey (NFHS-3), 2005-06: India: Volume I. Available from: http://cbhidghs. nic.in/writereaddata/linkimages/NFHS-3\%20 key\%20 Findings5456434051.pdf [Last accessed on 2013 Aug 17].

3. Garg PK, Jain BK, Choudhary D, Chaurasia A, Pandey SD. Nonscalpel vasectomy as family planning method: A battle yet to be conquered. ISRN Urol 2013;2013:752174.

4. Tuladhar H, Marahatta R. Awareness and practice of family planning methods in women attending gyne OPD at Nepal Medical College Teaching Hospital. Nepal Med Coll J 2008;10:184-91. 